Journal of Applied Pharmaceutical Science Vol. 6 (11), pp. 059-062, November, 2016

Available online at http://www.japsonline.com

DOI: $10.7324 / \mathrm{JAPS} .2016 .601109$

ISSN 2231-3354 (cc) EY-NC-SA

\title{
Cost of illness in psoriasis patients on Bath PUVA therapy versus Methotrexate
}

\author{
Swapna Satheendran ${ }^{\mathrm{a}}$, Anantha Naik Nagappa ${ }^{\mathrm{b}}$, Surulivel Rajan $^{\mathrm{c}}$, Sathish Pai ${ }^{\mathrm{d}^{*}}$ \\ a Department of Pharmacology, Kasturba Medical College, Manipal University, Manipal 576104, Karnataka, India. \\ ${ }^{b}$ Department of Pharmacy Management, Manipal College of Pharmaceutical Sciences, Manipal University, Manipal (Retd), India. \\ ${ }^{c}$ Department of Pharmacy Practice, Manipal College of Pharmaceutical Sciences, Manipal University, Manipal, India. \\ ${ }^{\mathrm{d}}$ Department of Dermatology, Kasturba Hospital, Manipal University, Manipal 576104, Karnataka, India.
}

\section{ARTICLE INFO}

Article history:

Received on: 08/08/2016

Revised on: 17/08/2016

Accepted on: 26/09/2016

Available online: 29/11/2016

Key words:

Bath-PUVA; Methotrexate;

Cost of illness; Psoriasis.

\begin{abstract}
Psoriasis results in expenses to patients from many cost sources. Psoriasis treatment may result in considerable time and travelling costs, yet many studies fail to account for these costs. The objective of this study was to evaluate the economic burden of psoriasis in patients.

Methods: The study was based on 200 patients with psoriasis visiting a tertiary level dermatological clinic. The data was based on a patient questionnaire and clinical data from the medical records. Item costs were based on true costs charged from the patients and all time cost estimates were done.

Results: 200 patients with psoriasis were included in the study. Total costs were higher for patients receiving phototherapy than those receiving systemic treatment. The majority of the visit costs arose from hospitalization and only a small proportion were attributed to outpatient visits.

Conclusion: Visit charges and other patient investigations were estimated to play a minor role in the total cost of psoriasis incurred by patients, while travel costs and loss of pay comprised the majority of the costs, which should not be omitted in future studies regarding costs of treatments.
\end{abstract}

\section{INTRODUCTION}

Psoriasis is a dermatological condition that is chronic and progressive. It affects almost all surface of the body. It is associated with excessive growth of skin on the affected areas like the nails, palms, soles, elbows, knees, trunk, abdomen and back (Langley et al., 2005). There is no cure available as on date, but there are measures and medications that can help to decrease the vigorous symptoms which affect the quality of life which makes the patient feel negative and depressed. It is not contagious, many a times due to ignorance psoriasis patients are isolated for fear of getting infected by the family members. The dramatic representation of an uncontrolled psoriasis really affects the social life and employment prospects of the patient making the patient feel a downtrodden psyche affecting the lifestyle of a patient (Gerald et al., 1998). The psoriasis aetiology indicates strong immune connection which is very much confirmed in psoriatic arthritis. It is estimated that $2 \%$ of world population is

\footnotetext{
* Corresponding Author

Email:drsbpai@yahoo.co.in
}

having psoriasis (Krueger and Bowcock, 2005). The present study is about cost of illness of treatment of psoriasis for different approaches of treatment available. The therapeutic treatment of psoriasis is mainly guided by the stages of psoriasis which is based on psoriasis area severity index (PASI) score. The PASI score categorizes psoriasis into mild, moderate and severe (Carlin CS et al., 2004). The treatment options available include topical steroids, coal tar application, oral methotrexate, retinoids, cyclosporine, UVB phototherapy and photochemotherapy (PUVA). The topical agents are commonly used for mild condition and in case of a very widespread disease, while phototherapy can be used for moderate and severe disease; and systemic agents including oral agents, and biological agents are available (Menter and Griffiths, 2007). Psoriasis exerts a substantial clinical, psychological and economic burden making the patients depressed, anxious and fearful. The degree of burden experienced by patients with psoriasis is comparable to patients who may have many chronic conditions, such as heart disease, diabetes, arthritis, stroke and congestive heart failure (Lee et al., 2010). 
In this study the treatment options that we have considered are patients on phototherapy with topical or systemic agents with topical therapy only. The cost of illness was computed as these treatments are the benchmark for physicians and patients, which is based on the systemic side effects profile of the drugs as well as the PASI score (Carlin et al., 2004).

In this study, the direct costs are prescription medications, consultations, inpatient medical visits, outpatient medical visits; hospitalization, phototherapy costs along with overthe-counter medications and the indirect costs are loss of productivity. Although PASI scores gives an idea regarding the status of disease, when it comes to treatment physicians face a daunting task of convincing patients regarding the cost of illness to the patients from time to time which may go up or go down, during the course of the disease.

Psoralen photochemotherapy (PUVA) is the combined use of psoralens (P) and long-wave UV radiation (UVA) and this combination produces a therapeutic response which is not attained when used as a solitary agent. A phototoxic reaction is induced which helps in the remission of the disease (Honigsmann, 2001). Psoralens are a group of phototoxic compounds that can interact with various components of cells and then absorb photons to produce photochemical reaction that alter the function of the cellular constituents. Parrisch et al. (1974), developed a powerful source of UVA and utilized it after 8 MOP administration in the treatment of psoriasis and coined the term PUVA. In 1982, the Food and Drug Administration (FDA) approved the use of PUVA treatment in the management of severe psoriasis (Gonzalez, 2001). Further the phototherapy is supplemented with topical treatment. The bath PUVA therapy is given intermittently depending on the PASI score and the symptoms visible on the skin. Srinivas et al have recommended a starting dose of $4-6 \mathrm{~J} / \mathrm{cm}^{2}$ with increments of $0.5 \mathrm{~J} / \mathrm{cm}^{2}$ depending on response. The maximum dose suggested is $18 \mathrm{~J} / \mathrm{cm}^{2}$. The treatment is given 3 - 4 times per week (Srinivas et al., 1997). In systemic treatment immunosuppressant like methotrexate are administered per oral on a dosing schedule of weekly once. The patients on methotrexate are given folic acid after two days.

\section{METHODS}

\section{Study design}

This was a prospective observational study that was conducted at a tertiary care hospital, in India. The patients who were greater than 18 years of age, either gender who visited or admitted in the dermatology department were included in the study. The patients diagnosed with psoriasis on Bath PUVA treatment or methotrexate between July 2013 and August 2014 were recruited. The study was approved by the institutional ethical committee (Ref. No: IEC 253/2013) of the hospital.

\section{Data collection}

The sociodemographic details of the patients like the gender, age, number of members living in the household, habits such as smoking and alcohol and if there is any hereditary trait, the income and the duration of the disease were collected. In order to know and to evaluate the extent of hospital services used by the patient and to identify the time spent by the patients on hospital visits alone, the following aspects were asked and noted down. The aspects that were considered were, the number of times they had to visit the hospital for the procedure or for consultation with regards to psoriasis in the past one year, the out-of-pocket expenses borne by the patients, the distance that had to be covered by the patient, the means they used to travel and the money spent on each time of this travel. The patient's records were used to take the data on the medication, supportive drugs and any other products they were using that were out-of- pocket expenses.

\section{RESULTS}

A total number of 200 patients were enrolled during the study period. The other demographic details such as age, sex, family history, social habits and co-morbidities, are summarized in Table 1 (a \& b).

Table 1(a): Demographic Characteristics.

\begin{tabular}{lll}
\hline & & No of patients \\
\hline Gender & Males & 129 \\
\hline Age(Years) & Females & 71 \\
& $18-30$ & 29 \\
& $31-50$ & 64 \\
& $51-70$ & 88 \\
& $>70$ & 19 \\
\hline Working Status & Working & 76 \\
& Non-Working & 124 \\
\hline Marital Status & Married & 151 \\
& Unmarried & 39 \\
& Widower & 4 \\
& Divorced & 6 \\
\hline
\end{tabular}

Table 1(b): Demographic Characteristics.

\begin{tabular}{ll}
\hline Family History & No of patients \\
\hline Yes & 106 \\
No/don't know & 94 \\
\hline Social habits & 114 \\
\hline Smokers & 86 \\
Non smokers & 106 \\
Alcoholics & 94 \\
Non-alcoholics & \\
\hline Mode of transport & 113 \\
\hline Bus & 7 \\
Auto & 73 \\
Car & 7 \\
Bus and Auto & \\
\hline Comorbidities & 61 \\
\hline Diabetes Mellitus & 59 \\
Hypertension & 17 \\
Arthritis & 39 \\
Dyslipidemia & 8 \\
Thyroid & 5 \\
Asthma &
\end{tabular}

\section{Bath PUVA group}

Out of 100, the average total direct medical cost per patient on bath PUVA was 7827 rupees, direct non-medical cost was 1200 rupees and indirect cost was 12540 rupees. The average 
total cost for the treatment of psoriasis per patient was found to be 22030 rupees. The individual total direct medical cost components of psoriatic patients on bath PUVA are summarized in the Table 2. Out of 100 patients on phototherapy, the results have shown that this treatment has been expensive but effective at the same time and considering the non-use of any systemic medication during this time is shown to be worthwhile.

Table 2 \& 3: Comparison of annual costs for BATH PUVA.

\begin{tabular}{ll}
\hline Direct Medical Cost (in rupees) & Mean SD \\
\hline Procedure & $1594 \pm 541$ \\
Drugs & $1247 \pm 43$ \\
Hospitalization & $4986 \pm 1773$ \\
Total direct cost & $7827 \pm 2357$ \\
\hline
\end{tabular}

Table 3:

\begin{tabular}{lll}
\hline Direct Non-Medical cost (in rupees) & Median & Range \\
\hline Food/transportation/Accommodation & 1200 & $(562,3887)$ \\
\hline Indirect Cost & Mean SD & \\
\hline Loss of pay & $12540 \pm 8654$ & \\
Total (Direct and Indirect Cost) & $\mathbf{2 2 0 3 0 \pm 9 3 4 0}$ & \\
\hline
\end{tabular}

\section{Methotrexate group}

Out of 100, the average total direct medical cost per patient on methotrexate was 233 rupees, direct non-medical cost was $\square$ rupees 500 and indirect cost was rupees 3480 . The average total cost for the treatment of psoriasis per patient was found to be rupees 4213 . The individual total direct medical cost components of psoriatic patients on methotrexate are summarized in the Table 4. Out of 100 patients on methotrexate, the results have shown that this treatment has been cheaper and effective at the same time.

Table 4: Comparison of annual costs for Methotrexate group.

\begin{tabular}{ll}
\hline Cost Components (in rupees) & Mean, SD \\
\hline Direct & - \\
Procedure & $233 \pm 83$ \\
Drugs & - \\
Hospitalization & \\
\hline Direct non-medical costs & 500 mean \\
\hline Food/transportation/Accommodation & \\
\hline Indirect Cost & $3480 \pm 540$ \\
\hline Loss of pay & 4213 \\
\hline Total (Direct and Indirect Cost)
\end{tabular}

\section{DISCUSSION}

In this study, the amount spent for medications encompassed only a small part of the total costs for a patient, while the loss of pay or absenteeism and hospitalizations were estimated to contribute to the majority of the costs to patients. The estimated cost of illness for patients with psoriasis on phototherapy was 22030 rupees per person per year, including costs due to hospitalization and the amount for patients on methotrexate was 4213 rupees. A study conducted in Malaysia showed that the treatment for psoriasis amounted to RM1307.47 excluding costs of hospitalization which was clearly much lower when compared to other studies in USA, Germany, and Australia (Min Moon Tang et al., 2013). A study by Javitz et al., disclosed that the yearly cost treatment excluding the investigations in USA was approximately US\$452 per person. A study in Australia, showed that the average cost for the management of psoriasis was shown to be AU\$439.53 per person per year (Jenner et al., 2002). A study conducted in Germany showed that the cost of illness in psoriasis amounted to $€ 6709.00$ per patient per year (Schöffski et al., 2007).

Some studies in the US (Yentzerand Feldman, 2011) showed that the out-of-pocket costs were lower for patients as they were on biologic therapies over phototherapy. In this study we have not compared as the usage of biologic therapies in this set up was not so frequent in comparison to bath PUVA and methotrexate.

Countries have unpredictable social security systems and compensation charges so direct comparison between studies has been considered problematic (Raho et al., 2012; Schöffski et al., 2007; Carrascosa et al., 2006). The medication costs to patients in this study may not be directly generalizable to other countries as it is not based on national policy as India does not have a standard healthcare system that can be compared to the rest of the countries. In the present analysis, indirect costs are higher than direct costs for patients with psoriasis. It should be pointed out that hospitalization represents the most significant item contributing to the total cost. As per the results obtained here, it shows that bath PUVA has a constructive long term effect in the progression of the disease while methotrexate is a cheaper option that patients may go for. Our study has indicated the methotrexate group is cheap compared to Bath PUVA because the methotrexate patients are treated as out patients and do not need to be admitted in the hospital, whereas the bath PUVA patients require hospitalization. However, the cost of the bath PUVA can also be controlled by day care option for the patients.

\section{CONCLUSION}

Psoriasis represents an important cause of economic burden in India, both to the society and the system. The cost of illness of two groups of patient undergoing two therapeutic modalities was studied and the total cost of Bath PUVA therapy (22030 rupees) was higher that of the Methotrextae group (4213 rupees). This study highlighted the financial burden to psoriasis patients. These data might be useful for health care planners for appropriate planning for health care provision.

\section{Financial support and sponsorship: Nil.}

Conflict of Interests: There are no conflicts of interest.

\section{REFERENCES}

Carlin CS, Feldman SR, Krueger JG, Menter A, Krueger GG. A $50 \%$ reduction in the Psoriasis Area and Severity Index (PASI 50) is a clinically significant endpoint in the assessment of psoriasis.J Am Acad Dermatol, 2004; 50(6):859-66.

Carrascosa JM, Pujol R, Dauden E, et al. A prospective evaluation of the cost of psoriasis in Spain (EPIDERMA project: phase II). J Eur Acad Dermatol Venereol, 2006; 20(7):840-845. 
Gerald Krueger, John Koo, Mark Lebwohl, Alan Menter, Robert S. Stern, Tara Rolstad. The Impact of Psoriasis on Quality of Life Results of a 1998 National Psoriasis Foundation Patient-Membership Survey. Arch Dermatol, 2001; 137(3):280-284.

Gonzalez E. PUVA for psoriasis. Dermatologic Clinics, 1995; 13(4): 851-71.

Honigsmann H. Phototherapy for psoriasis: Review article. Clin Exp Dermatol, 2001; 26: 343-50

Javitz HS, Ward MM, Farber E, et al. The direct cost of care for psoriasis and psoriatic arthritis in the United States. $J$ Am Acad Dermatol2002; 46: 850-860.

Jenner N, Campbell J, Plunkett A, Marks R. Cost of psoriasis: a study on the morbidity and financial effects of having psoriasis in Australia. Australas J Dermatol2002; 43: 255-261.

Krueger J, Bowcock A. Psoriasis pathophysiology: current concepts of pathogenesis. Ann Rheum Dis. 2005 Mar; 64(Suppl 2): ii30ii36.

Langley RGB, Krueger GG, Griffiths CEM. Psoriasis: epidemiology, clinical features, and quality of life. Ann Rheum Dis 2005;64:ii18-ii23

Lee YW, Park EJ, Kwon IH, Kim KH, Kim KJ. Impact of Psoriasis on Quality of Life: Relationship between Clinical Response to Therapy and Change in Health-related Quality of Life. Ann Dermatol, 2010; 22(4): 389-396.

Menter A, Griffiths CE. Current and future management of psoriasis. Lancet. 2007; 370(9583):272-84.

Parrish JA, Fitzpatrick TB, Tanenbaum. Photochemotherapy of psoriasis with oral methoxsalen and long wave ultraviolet light. N Engl J Med 1974;291:1207-11.

Raho G, Koleva DM, Garattini L, Naldi L. The burden of moderate to severe psoriasis: an overview. Pharmacoeconomics. 2012; 30(11):1005-1013.
Schöffski O, Augustin M, Prinz J, et al. Costs and quality of life in patients with moderate to severe plaque-type psoriasis in Germany: a multi-center study. J Dtsch Dermatol Ges, 2007; 5: 209-218.

Srinivas CR, Shenoi SD, Sathish Pai. Psoralen. Ind J Dermatol Venerol Leprol, 1997;63:276-87.

Tang MM, Chang CC, Chan LC, and Heng A. Quality of life and cost of illness in patients with psoriasis in Malaysia: a multicenter study. International Journal of Dermatology Volume 52, Issue 3, pages 314-322, March 2013

Yentzer BA, Feldman SR. Trends in home phototherapy adoption in the US: monetary disincentives are only the tip of the iceberg. J Dermatol Treat. 2011;22(1):27-30.

\section{How to cite this article:}

Satheendran S, Nagappa AN, Rajan S, Pai S. Cost of illness in psoriasis patients on Bath PUVA therapy versus Methotrexate. J App Pharm Sci, 2016; 6 (11): 059-062. 